Article

\title{
Determination of Volatile Fuel Oxygenates in Water by Gas Chromatography-Triple Quadrupole Mass Spectrometry: Effect of Automated Sample Preparation Techniques
}

\author{
Kai Zhu ${ }^{1, * \mathbb{D}}$, Yucan Liu ${ }^{2, *}$, Qing Sun ${ }^{3}$, Min Zhao ${ }^{1}$ and Lihua Huang ${ }^{1}$ \\ 1 Shandong Provincial Key Laboratory of Water and Soil Conservation and Environmental Protection, \\ College of Resources and Environment, Linyi University, Linyi 276000, China; zhaomin@lyu.edu.cn (M.Z.); \\ huanglihua@lyu.edu.cn (L.H.) \\ 2 School of Civil Engineering, Yantai University, Yantai 264005, China \\ 3 Municipal Engineering Design Institute, Linyi Architectural Design \& Research Institute Co., Ltd., \\ Linyi 276000, China; sunqing198905@163.com \\ * Correspondence: zhukai@lyu.edu.cn (K.Z.); liuyucan@ytu.edu.cn (Y.L.)
}

Received: 5 July 2020; Accepted: 8 August 2020; Published: 12 August 2020

\begin{abstract}
Considering the adverse effects of gasoline additives and aromatic compounds on the quality of the water supply and the ecological environment of the water, a methodology, with short chromatographic separation time (22.5 min) and high separation quality, was optimized for the determination of 11 common gasoline additives and aromatic compounds using gas chromatograph coupled with triple quadrupole mass spectrometer (GC-QqQ-MS/MS) system. The extraction procedure of analytes was performed by headspace solid-phase microextraction (HS-SPME) and purge and trap (P\&T), respectively. Both of the two extraction methods provided excellent chromatographic resolution in subsequently GC-QqQ-MS/MS detection system, with the coefficients of linear regression of the calibration curves with HS-SPME and P\&T pretreatments were 0.9965 0.9998 and 0.9961 0.9999, respectively, $n=7$. The limit of detections (LODs) of these selected oxygenate compounds were discovered to be $0.52 \sim 32 \mathrm{ng} / \mathrm{L}$ in the P\&T-GC-QqQ-MS/MS detection system and 0.11 151 ng/L in the HS-SPME-GC-QqQ-MS/MS detection system. For benzene, toluene, ethylbenzene and xylene isomers (BTEX), the HS-SPME-GC-QqQ-MS/MS system provided outstanding detection performance because of the lower LOD obtained. However, for other selected compounds, the P\&T-GC-QqQ-MS/MS system offered lower LODs. The proposed extraction-detection procedure is a simple and sensitive analytical approach for the detection of gasoline additives and aromatic compounds in water.
\end{abstract}

Keywords: purge and trap; headspace solid-phase microextraction; gasoline additives; aromatic compounds; gas chromatography-triple quadrupole mass spectrometry

\section{Introduction}

Gasoline additives, a group of octane number enhancers, are added to gasoline in order to increase the combustion efficiency and reduce the generation of $\mathrm{CO}$ [1]. The gasoline-derived contaminants enter into water through fuel spills include varieties of toxic chemicals, such as methyl tert-butyl ether (MTBE), tert-butyl alcohol (TBA), tert-butyl formate (TBF), oxygenate dialkyl ethers (ETBE), tert-amyl methyl ether (TAME), diisopropyl ether (DIPE)) and aromatic compounds (benzene, toluene, ethylbenzene and xylene isomers (BTEX)) [2]. According to the Clean Air Act Amendments of United States Environmental Protection Agency (US EPA), MTBE, added to gasoline at $10 \%(v / v)$, is the 
most commonly used oxygenate [3]. Because of its massive use, refractory biodegradation and high solubility, MTBE has become one of the most frequently detected pollutants in groundwater and surface water $[4,5]$. MTBE is proved to be carcinogenic to animals and the US EPA has issued a drinking water advisory for MTBE at 20 40 $\mu \mathrm{g} / \mathrm{L}$ to protect the public health [6-8]. Furthermore, TBA, TBF and the primary metabolite of MTBE were detected in gasoline polluted waters [9]. TBF is generally rapidly transformed to TBA in aqueous solutions and TBA is a proven neurotoxin at higher doses [10,11]. BTEX exhibited carcinogenic effects, and accounts for around 18\% (w/w) in gasoline [12]. The US EPA established a drinking advisory to protect public health, recommending the concentration of benzene, toluene, ethylbenzene and xylenes below $5 \mu \mathrm{g} / \mathrm{L}, 1 \mathrm{mg} / \mathrm{L}, 0.7 \mathrm{mg} / \mathrm{L}$ and $10 \mathrm{mg} / \mathrm{L}$, respectively [13].

Detection of fuel oxygenates and BTEX has become increasingly important to environmental and water quality management. The analysis of these contaminants normally involves sample pretreatments, including solid-phase microextraction (SPME) [14-16], purge-and-trap (P\&T) [9,17-19] and headspace (HS) [20]. Direct aqueous injection (DAI) during gas chromatography-mass spectrometry (DAI-GC-MS) detection of fuel oxygenates and BTEX was studied [21]. Although DAI is an efficient method without pre-treatment steps, the reported limit of detections (LODs) were much higher than those using GC-MS with P\&T pretreatment [9]. Due to the excellent extraction performance of polymeric coating on fused silica fiber, SPME exhibits remarkable pretreatment efficiency [22]. In SPME, these adsorbed analytes dissociated during heating into gas chromatograph (GC) injection port process, providing a simple and sensitive method. SPME technology completes sampling, extraction, pre-concentration and sample injection in one-step, sharply decreased the noise, and improved the extraction efficiency [23].

P\&T-GC/MS is the most commonly used technique for analyzing fuel oxygenates and BTEX in water [7]. This method has been widely assessed and frequently used for the detection of fuel oxygenates in surface and ground waters. Nevertheless, the LOD of TBA in the P\&T-GC/MS process is higher than other fuel oxygenates, because of its high polarity and low Henry's constant [16]. With the development of technology, Rosell et al. [9] reported an exceeding low LOD for MTBE (1 ng/L) and TBA (110 ng/L) through the P\&T-GC/MS method.

During multiple reactions monitoring (MRM) mode of the GC-QqQ-MS/MS detection process, analytes can be identified sensitively and selectively [24]. The MRM mode has been widely used for the detection of micro pollutants in soil, air and water [25]. However, based on our study on published literatures, few studies reported the detection of fuel oxygenates and BTEX in water using GC-QqQ-MS/MS with HS-SPME and P\&T systems. The aim of present paper is to develop two determination methods based on the pretreatment of SPME and P\&T using GC-QqQ-MS/MS, comparing analytical performance of the two proposed pretreatment methods. Meanwhile, parameters optimization of the detection methods has been provided and discussed.

\section{Materials and Methods}

\subsection{Chemicals and Reagents}

Standard DIPE, MTBE- $d_{3}$ (internal standard, IS $_{1}$ ) solution and a mixture of BTEX and MTBE in methanol at individual concentrations of $2000 \mathrm{mg} / \mathrm{L}$ were purchased from Sigma-Aldrich. Standard TBA (2000 mg/L), TAME (200 mg/L), TBF, ETBE and fluorobenzene (200 mg/L, internal standard, $\left.\mathrm{IS}_{2}\right)$ were purchased from J\&K. Methanol (high performance liquid chromatography grade) was obtained from Sigma-Aldrich. Ultra-pure water $(18.2 \mathrm{M} \Omega \cdot \mathrm{cm}$, total organic carbon $<1 \mu \mathrm{g} / \mathrm{L})$ used in present research was obtained from an Elga Purelab Ultra Analytic system (Bucks, UK).

\subsection{Standard Solutions Preparation}

The standard stock solution of individual analyte at concentration of $500 \mu \mathrm{g} / \mathrm{L}$ was formed using ultra-pure water. All stock solutions were configured once a week, keeping in amber bottles at $4{ }^{\circ} \mathrm{C}$ in a freezer before using. Standard calibration solutions of 20,10, 5, 1, 0.5, 0.1, $0.05 \mu \mathrm{g} / \mathrm{L}$ used in present study were obtained by step wisely diluting the $500 \mu \mathrm{g} / \mathrm{L}$ stock solution to the specified concentrations 
with ultra-pure water. Standard calibration solutions were used to establish the calibration curves and obtain LODs and limit of quantification (LOQs) of each analyte.

The standard stock solution of IS1 at $40 \mathrm{~g} / \mathrm{L}$ was configured by dissolving $2 \mathrm{~g}$ MTBE- $d_{3}$ in $50 \mathrm{~mL}$ amber volumetric flask using HPLC grade methanol. The fluorobenzene $\left(\mathrm{IS}_{2}\right)$ solution at concentration of $8 \mathrm{mg} / \mathrm{L}$ was obtained by dispensing $2 \mathrm{~mL}$ of the solution into a $50 \mathrm{~mL}$ volumetric flask, using methanol as solvent.

\subsection{Sampling}

A water sample was prepared based on standard water sampling techniques for volatile organic compounds by the US EPA (Method 8260). Water samples were collected in duplicate from different places directly in the vials. The vessels were filled up with water in order to shun headspace. After sampling, these water samples were cooled down to $4{ }^{\circ} \mathrm{C}$ in a refrigerator before analysis (within one week). The surface water samples were withdrawn from Xi'an Shi-bian-yu reservoir and the groundwater samples were taken from a well in outskirts of $\mathrm{Xi}^{\prime}$ an city.

\section{4. $G C-Q q Q-M S / M S$ Analysis}

The detection of volatile fuel oxygenates and BTEX was conducted with a 7890A gas chromatograph coupled with 7000A triple quadrupole mass spectrometer (GC-QqQ-MS/MS) (Agilent Technologies, Palo Alto, CA, USA). The separation of these analytes during detection process was performed using a $75 \mathrm{~m} \times 0.53 \mathrm{~mm}$ I.D. DB-624 fused-silica capillary column (J\&W Scientific, Folsom, CA, USA). In the separation process, the column temperature was kept at $35^{\circ} \mathrm{C}$ for $1 \mathrm{~min}$. After that, the temperature was increased to $95^{\circ} \mathrm{C}$ at $8{ }^{\circ} \mathrm{C} / \mathrm{min}$ and hold at $95^{\circ} \mathrm{C}$ for $3 \mathrm{~min}$. Then, the temperature was increased from 95 to $225^{\circ} \mathrm{C}$ at $13^{\circ} \mathrm{C} / \mathrm{min}$ for $1 \mathrm{~min}$. The total time of the separation process was $22.5 \mathrm{~min}$. Helium was used as carrier gas fixed at $3 \mathrm{~mL} / \mathrm{min}$ and nitrogen was used as collision gas with $1.5 \mathrm{~mL} / \mathrm{min}$.

Electron ionization (EI) was used before analytes went into the QqQ mass spectrometer analysis, ionization voltage was fixed at $70 \mathrm{eV}$ and the temperature of ionization source was $230^{\circ} \mathrm{C}$. The filament multiplier delay is $11 \mathrm{~min}$ for SPME and $12 \mathrm{~min}$ for P\&T. The emission current was set at $35 \mu \mathrm{A}$ and the dwell times were optimized between 80 and $240 \mathrm{~ms}$ [26].

\subsection{Purge and Trap Equipment}

During P\&T preparation process, a Tekmar purge-and-trap concentrator together with an Aquatek 100 liquid autosampler was used to prepare samples. Before preparation process, a $5 \mathrm{~mL}$ water sample was extracted and transferred to purge tube of the concentrator. A $40 \mathrm{~mL} / \mathrm{min}$ high purity nitrogen was used to purge analytes from water and these purged organics were trapped by Tenax-Silica gel-charcoal trap. Afterwards, the trap was heated to $280^{\circ} \mathrm{C}$ for the desorption of trapped organics using helium as carrier gas. During the analysis process, sampling needle and purge tube were washed with HPLC water and the trap was baked at $280^{\circ} \mathrm{C}$ for $4 \mathrm{~min}$ before next sample injection in order to ensure accuracy.

\subsection{Solid-Phase Microextraction Equipment}

The commercial extraction fiber (50/30 mm polydimethylsiloxane/divinylbenzene/carboxen (PDMS/DVB/CAR)) for SPME preparation was obtained from Supelco. All these fibers used in SPME preparation were conditioned complied with the manufacture's recommendations in the injection port of the GC system. A $8 \mathrm{~mL}$ water sample, in a $15 \mathrm{~mL}$ vial, was mixed under intense magnetic stirring. The vial was sealed using silicon-Teflon septum cap after adding $2.0 \mathrm{~g} \mathrm{NaCl}$ to water sample. Subsequently, the sealed vial was transported to water-bath at $40^{\circ} \mathrm{C}$ for $30 \mathrm{~min}$ with vigorous magnetic stirring. The needle outside the fiber was employed to penetrate the septum in order to allow the fiber extended into the headspace for analytes extraction. The extracted fiber was placed into the glass liner of the GC injection port and these analytes were desorbed from the fiber at $230{ }^{\circ} \mathrm{C}$ for $4 \mathrm{~min}$. 


\subsection{Optimization of the MS/MS Parameters}

These analytes and two internal standards $\left(\mathrm{IS}_{1}\right.$ and $\mathrm{IS}_{2}$ ) were analyzed under scan mode in order to optimize the MS/MS analysis parameters and identify the precursor ions of each analyte in data acquisition systems. Mass spectra obtained in full scan mode were recorded to identify the higher mass ratios and abundance ions of these analytes, to increase the selectivity and sensitivity of the detection method [27]. After the full scan mode, the daughter ion scan mode was conducted to identify the product ions of each analyte. Daughter ions were produced by adopting collision energy voltages $(5 \sim 65 \mathrm{eV})$ and the analytes molecules under collision induced dissociation (CID), using nitrogen gas as the collision gas.

\section{Results and Discussion}

\subsection{Selection of Precursor Ions and Product Ions}

The $m / z$ obtained in full scan mode for the selected analytes is shown in Supplementary Materials Figure S1. On the basis of the definition of identification points (IPs) in the Decision 2002/657/EC, 1.0 IP and 1.5 IPs are appointed to precursor ion and product ion during MS/MS analysis, respectively. An unambiguous confirmation of the analytes identity needs 3 or 4 identification ions [28]. Even though the definition was originated from the determination of organics in animal products, it has been used in the analysis of trace contaminants in environmental matrices [29].

In the present research, the detected $m / z$ range was set at 40 200 and the applied EI energy was fixed at $70 \mathrm{eV}$ in MS full scan mode, those fragments with high abundance ratios and high $\mathrm{m} / \mathrm{z}$ were selected as precursor ions in MRM mode [30]. Nitrogen was used as the collision gas during product ion scan mode, the product ion and the optimal collision energy for each of the selected analytes were determined. In order to make sure that the chromatographic peaks of the analytes under test were at least ten points and satisfy the analysis requirement, the test time is divided into seven periods, dwell time is set to $80 \sim 240 \mathrm{~ms}$. For each of the selected analytes, one precursor ion with two different product ions at specific collision energy (CE) voltage were monitored (see Table S1).

\subsection{Effect of Inlet Temperature}

The influence of the inlet temperature on signal detection intensities during the detection process on the basis of the mentioned GC-QqQ-MS/MS conditions was investigated. A $1 \mu \mathrm{L}$ mixed standard solution of the selected analytes at individual concentration of $20 \mu \mathrm{g} / \mathrm{L}$ was injected into GC-QqQ-MS/MS detection system with matched autosampler under six individual injection-port temperatures $\left(150,170,190,210,230\right.$ and $250^{\circ} \mathrm{C}$ ) in splitless mode. Each detection of the sample was repeated three times. The relative signal intensities of these identified peaks of the selected analytes with reference to those at $250{ }^{\circ} \mathrm{C}$ were calculated using Equation (1). The results are shown in Figure 1a,b.

$$
\text { Ratio }(\%)=\left(\text { Peak area at } \mathrm{T} / \text { Peak area at } 250{ }^{\circ} \mathrm{C}\right) \times 100 \%
$$

As can be seen from Figure 1, the effect of the injection port temperature on signal detection intensities of the selected analytes was complex. For MTBE, the effect of temperature on signal detection intensity was negligible. For ETBE and TBA, the intensity of signal increased obviously as the injection port temperature increased from 150 to $230^{\circ} \mathrm{C}$. However, as the temperature further increased to $250^{\circ} \mathrm{C}$, the intensity exhibited decreased tendency. The intensity of response signal for the other analytes exhibited increased tendency as the temperature increased from 150 to $210^{\circ} \mathrm{C}$, then decreased as the temperature further increased to $250^{\circ} \mathrm{C}$. Hence, the temperature of injection port was fixed at $210^{\circ} \mathrm{C}$. 

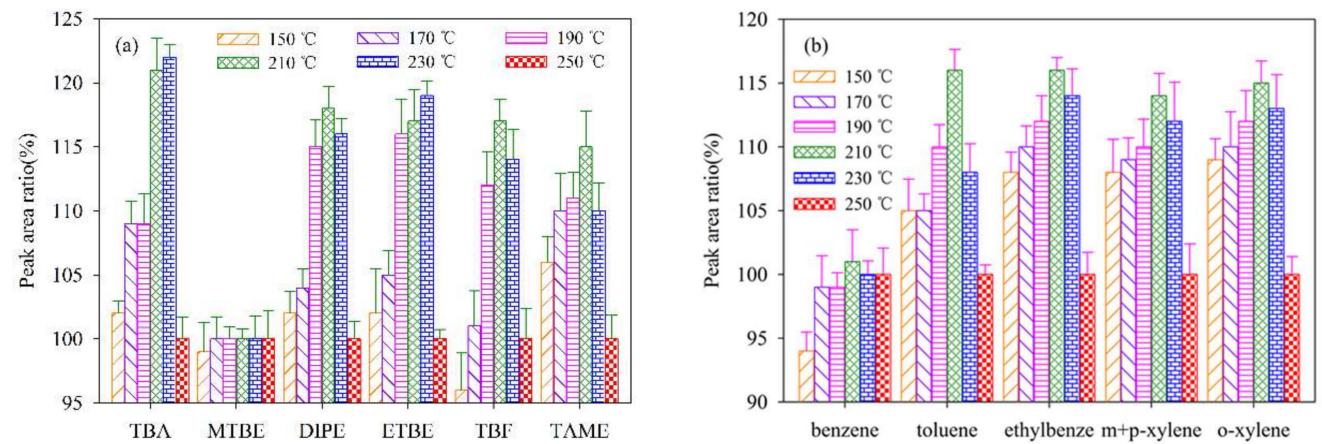

Figure 1. Effect of injection port temperature on MS/MS detection signal intensities of the twelve analytes $(20 \mu \mathrm{g} / \mathrm{L})$. The peak area at the injection port temperature of $250{ }^{\circ} \mathrm{C}$ is used as a reference $(100 \%)$. (a) the peak area ratio of TBA, MTBE, DIPE, ETBE, TBF, and TAME; (b) the peak area ratio of benzene, toluene, ethylbenze, $\mathrm{m}+\mathrm{p}-\mathrm{xylene}$, and $\mathrm{o}-\mathrm{xylene}$.

\subsection{Optimization of Purge and Trap (PET) Preparation}

\subsubsection{Effect of Sample Purge Temperature}

The influence of sample purge temperature on detection accuracy were investigated at 25, 30, 35, $40,45,50$ and $55^{\circ} \mathrm{C}$, respectively with the concentration of individual analyte at $20 \mu \mathrm{g} / \mathrm{L}$. The effects of purge temperatures on the sample purge efficiency are presented in Figure $2 \mathrm{a}, \mathrm{b}$.
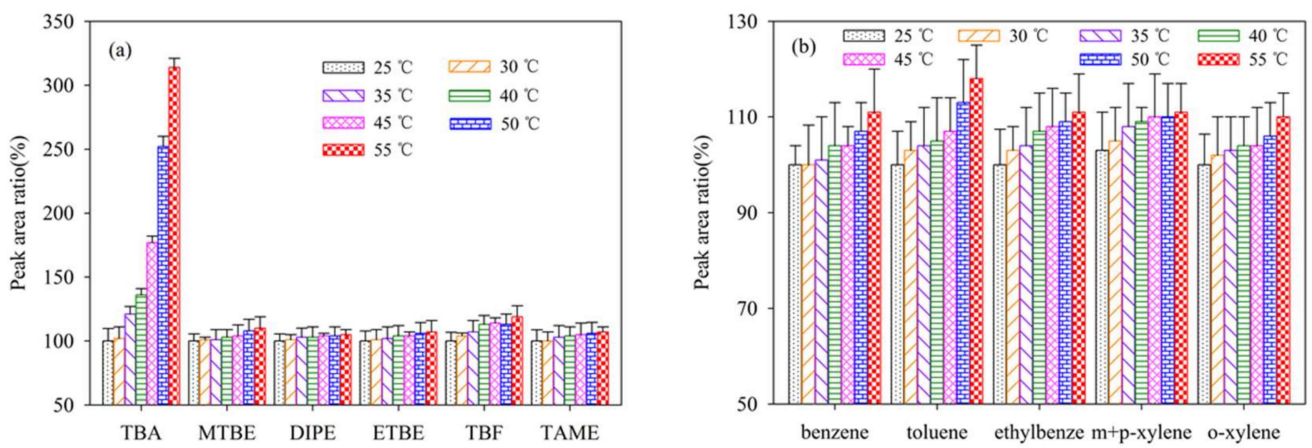

Figure 2. Effect of sample temperature on signal intensities of the twelve analytes $(20 \mu \mathrm{g} / \mathrm{L})$. The peak area at the sample temperature of $25{ }^{\circ} \mathrm{C}$ is used as a reference $(100 \%)$. (a) the peak area ratio of TBA, MTBE, DIPE, ETBE, TBF, and TAME; (b) the peak area ratio of benzene, toluene, ethylbenze, $\mathrm{m}+\mathrm{p}-\mathrm{xylene}$, and $\mathrm{o}-\mathrm{xylene}$.

For TBA, the signal intensity reached maximum at purge temperature $55^{\circ} \mathrm{C}$. This phenomenon reflects that high temperature could increase dissociation energy of TBA from water to strength the mass transfer process, since appropriate sample temperature during sample purge process could promote the purge of odorous compounds from water sample [31]. Hence, high purging temperature was favorable for TBA extraction. However, excessively high preparation temperature may cause water vapor transfer into the pyrolysis system, disturbing the gasification and the following adsorption-desorption process. Water vapor is bad for the exclude of interference of impurities in environmental water, due to the interference with water vapor and other substances in water. Hence, during the GC detection process, the sample purging temperature is generally set at about $40^{\circ} \mathrm{C}$ [32]. For this reason, the sample purging temperature of $40^{\circ} \mathrm{C}$ was selected for the P\&T method.

\subsubsection{Effect of Desorption Time}

The desorption time of P\&T preparation is also a fatal operating condition parameter, influencing the purging efficiency and detection sensitivity. The influence of desorption time on the signal intensities 
of selected analytes were examined, with individual concentrations of $20 \mu \mathrm{g} / \mathrm{L}$ at five different desorption times (1, 2, 3, 4 and $5 \mathrm{~min})$. As shown in Figure 3a,b, the ratio values increased significantly when the desorption time increased from 1 to $2 \mathrm{~min}$. However, when we further increased desorption time from 3 to $5 \mathrm{~min}$, the ratio values stayed pretty the same. This phenomenon indicated that 2 min was enough for these selected analytes to dissociate during detection process. Therefore, 2 min desorption time was designated for this detection method.
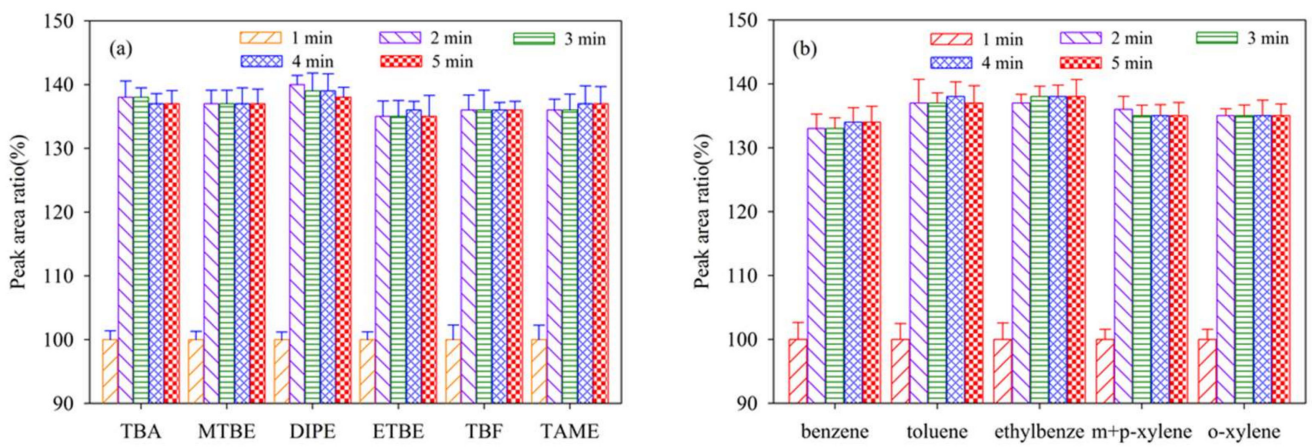

Figure 3. Effect of desorb time on signal intensities of the twelve analytes $(20 \mu \mathrm{g} / \mathrm{L})$. The peak area at the desorb time of $1 \mathrm{~min}$ is used as a reference (100\%). (a) the peak area ratio of TBA, MTBE, DIPE, ETBE, $\mathrm{TBF}$, and TAME; (b) the peak area ratio of benzene, toluene, ethylbenze, $\mathrm{m}+\mathrm{p}-\mathrm{xylene}$, and $\mathrm{o}-\mathrm{xylene}$.

\subsection{Optimization of SPME}

\subsubsection{Effect of Extraction Temperature}

Extraction temperature made great impact on the mass transfer rates and partition coefficients during SPME process. Hence, extraction temperature has significant influence on the extraction efficiency of organics [14].

Higher extraction temperature would promote the diffusion of volatile organic compounds and shorten the balance time between gas and liquid, especially during the SPME process [33]. However, higher extraction temperature could accelerate the desorption rate of low boiling point organics, which is unfavorable for detection. The effect of selected extraction temperatures $(20,30,40,50,60$ and $70{ }^{\circ} \mathrm{C}$ ) on the extraction efficiency of these analytes is shown Figure $4 \mathrm{a}, \mathrm{b}$.
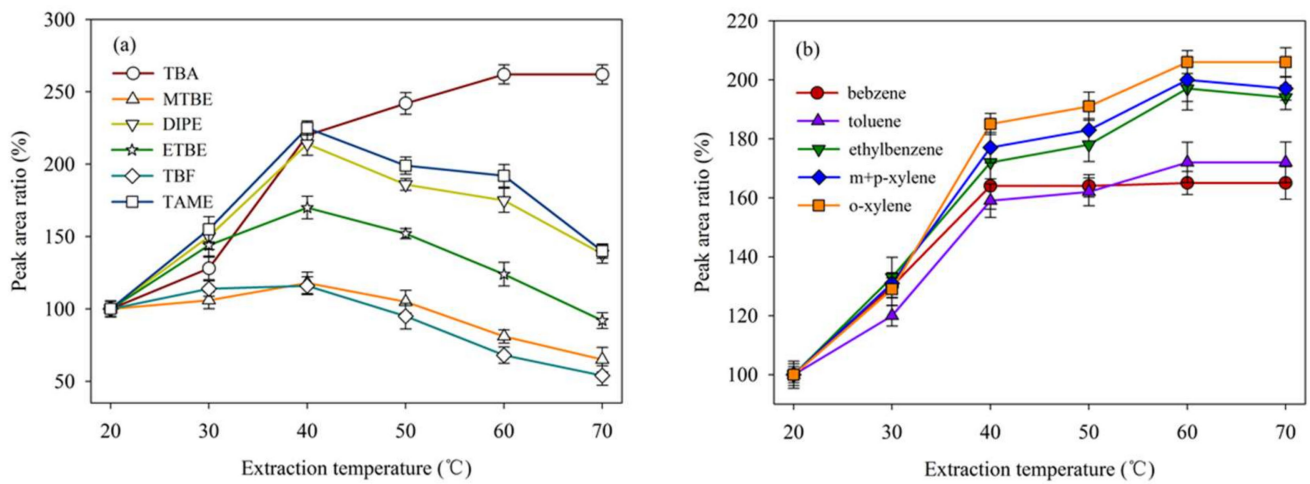

Figure 4. Effect of extraction temperature on signal intensities of the twelve analytes $(20 \mu \mathrm{g} / \mathrm{L})$. The peak area at the extraction temperature of $20{ }^{\circ} \mathrm{C}$ is used as a reference $(100 \%)$. (a) the peak area ratio of TBA, MTBE, DIPE, ETBE, TBF, and TAME; (b) the peak area ratio of benzene, toluene, ethylbenze, $\mathrm{m}+\mathrm{p}-\mathrm{xylene}$, and $\mathrm{o}-\mathrm{xylene}$.

As can be seen from Figure $4 a, b$, the extraction efficiency of TBA was greatly increased when the extraction temperature increased from 20 to $70^{\circ} \mathrm{C}$. For BTEX, the extraction efficiency exhibited 
increasing trend when the temperature increased from 20 to $40{ }^{\circ} \mathrm{C}$. It appears that higher extraction temperature was more favorable for TBA extraction. This phenomenon may cause by its relatively high melting point $\left(25.7^{\circ} \mathrm{C}\right)$ and boiling point $\left(82.42^{\circ} \mathrm{C}\right)$ compared to other selected analytes. However, for other analytes, the extraction efficiency increased in the temperature range of $20 \sim 40{ }^{\circ} \mathrm{C}$. Therefore, $40{ }^{\circ} \mathrm{C}$ was selected for the extraction temperature during SPME process.

\subsubsection{Effect of Extraction Time}

Due to the equilibrium distribution of organics during SPME process, the extracted organics would reach their maximum amount at the equilibrium time [16]. Stirring of water sample could improve the extraction of analytes due to the faster diffusion of organics to the solid fiber. Analytes, with low distribution constants, need excessive time to reach their equilibrium state [32]. Hence, extraction time is an important parameter during preparation process related to the extraction efficiency [33].

The influence of extraction times on the extraction efficiency in SPME process was significant (Figure 5). In order to ensure the accuracy of the detection, three replicate water samples were extracted in SPME system and detected in GC-QqQ-MS/MS system at each extraction time. The peak area ratios obtained in different extraction time indicated that the signal intensity increased sharply as the extraction time increased from 10 to $30 \mathrm{~min}$. After $30 \mathrm{~min}$ of extraction, further extension of extraction time had no impact on extraction efficiency. The above discussion indicated that 30 min sample extraction time was optimum processing time for the detection of selected analytes.
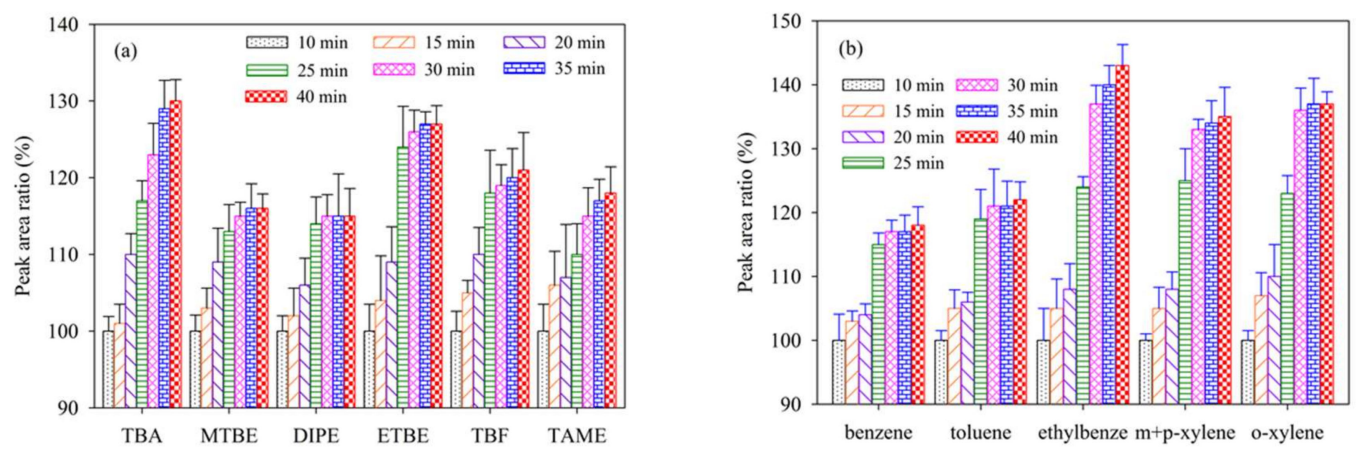

Figure 5. Effect of extraction time on signal intensities of the twelve analytes $(20 \mu \mathrm{g} / \mathrm{L})$. The peak area at the extraction time of $10 \mathrm{~min}$ is used as a reference (100\%). (a) the peak area ratio of TBA, MTBE, DIPE, ETBE, TBF, and TAME; (b) the peak area ratio of benzene, toluene, ethylbenze, $\mathrm{m}+\mathrm{p}-\mathrm{xylene}$, and o-xylene.

\subsubsection{Effect of Addition of $\mathrm{NaCl}$}

The addition of $\mathrm{NaCl}$ to water samples could promote the extraction of these oxygenate compounds during SPME preparation process. $\mathrm{NaCl}$ in solution could increase the ionic strength of water samples significantly, meanwhile, the aqueous solubility of oxygenate compounds would reduce in $\mathrm{NaCl}$ solution $[33,34]$. The effect of addition of $\mathrm{NaCl}$ on the extraction efficiency of these analytes is shown Figure $6 a, b$.

As shown in Figure 6, the effect of $\mathrm{NaCl}$ added into water samples was especially obvious for TBA and TAME. In order to suppress interference, three replicate water samples were extracted in SPME system and detected in GC-QqQ-MS/MS system at each $\mathrm{NaCl}$ concentration. The responses intensities of TBA and benzene were greatly increased as $\mathrm{NaCl}$ dosage increased from 2.0 to $2.8 \mathrm{~g}$. However, for other analytes, the responses intensity in GC-QqQ-MS/MS system was almost the same with different $\mathrm{NaCl}$ dosage. All further method evaluation was therefore made with $2.0 \mathrm{~g}$ added $\mathrm{NaCl}$. 

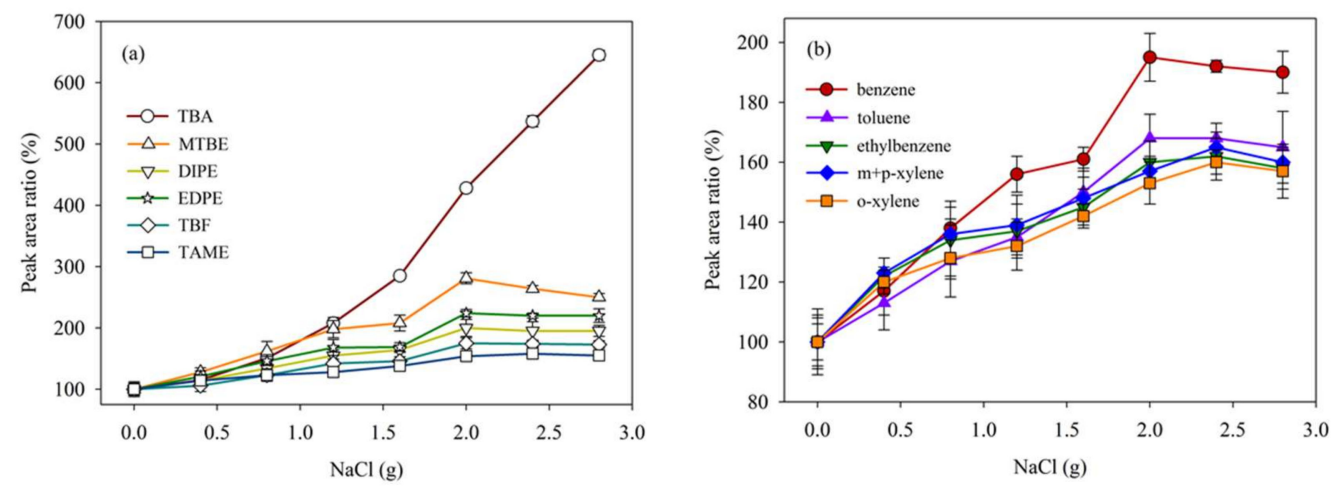

Figure 6. Effect of addition of $\mathrm{NaCl}$ on signal intensities of the twelve analytes $(20 \mu \mathrm{g} / \mathrm{L})$. The peak area at no salt added is used as a reference (100\%). (a) the peak area ratio of TBA, MTBE, DIPE, ETBE, TBF, and TAME; (b) the peak area ratio of benzene, toluene, ethylbenze, $m+p-x y l e n e$, and $o-x y l e n e$.

\subsection{Method Validation}

\subsubsection{Standard Calibration, Linearity and Sensitivity}

In order to develop the calibration curve of selected analytes in the present study, seven concentration levels were chosen $(0.05,0.1,0.5,1,5,10$ and $20 \mu \mathrm{g} / \mathrm{L})$ for the P\&T-GC-QqQ-MS/MS detection method and for the HS-SPME-GC-QqQ-MS/MS detection method under the MRM mode, respectively.

Therefore, so as to ensure the accuracy of the calibration curve, triplicate detections were performed for each water sample, the average value was chosen to plot the standard calibration curves of these analytes. Before GC-QqQ-MS/MS detection, all these water samples were pretreated by P\&T or SPME as described in Sections 3.3 and 3.4. The coefficients of linear regression $\left(r^{2}\right)$ of the calibration curves of these selected analytes in P\&T-GC-QqQ-MS/MS detection system and HS-SPME-GC-QqQ-MS/MS detection system were described in Tables S2 and S3, with $r^{2}$ ranged from 0.9961 to 0.9999.

It is remarkable that two internal standards, MTBE- $d_{3}$ and fluorobenzene, were added into water samples during each operation of the calibration standard solutions detection, eliminating the influence of real water matrix. The concentrations of MTBE- $d_{3}$ and fluorobenzene were fixed at $0.5 \mu \mathrm{g} / \mathrm{L}$ and $1 \mu \mathrm{g} / \mathrm{L}$ respectively. In the GC-QqQ-MS/MS detection system, LODs are described as the lowest concentrations of the analyte that can be detected to satisfy the statistical differences between water sample and blank sample [35]. In the GC-QqQ-MS/MS detection system of this study, LODs and LOQs of these selected oxygenate compounds were discovered to be $0.52 \sim 32 \mathrm{ng} / \mathrm{L}$ in the P\&T-GC-QqQ-MS/MS detection system method and 0.11 151 ng/L in HS-SPME-GC-QqQ-MS/MS detection system as shown in Tables S2 and S3.

\subsubsection{Method Precision and Accuracy of Two Methods}

The precision of the detection methods described in this study was deduced by calculating the relative standard deviations (RSDs) of the obtained signal intensities of the selected analytes at two fortification concentrations $(0.5$ and $5 \mu \mathrm{g} / \mathrm{L})$. The intra-day precision was calculated on the basis of five replicate detection $(n=5)$ results of each concentration in GC-QqQ-MS/MS detection system within one day. On the other hand, the inter-day precision was calculated on the basis of six days' detection $(n=6)$ results [34]. As shown in Tables S2 and S3, the intra-day $(n=5)$ and inter-day $(n=6)$ precision in this study for these selected oxygenate compounds were found in the range of $1.99 \sim 8.87 \%$ and 1.18 12.7\% with the P\&T-GC-QqQ-MS/MS detection system, and 1.19 9.65\% and 1.09 9.78\% with the HS-SPME-GC-QqQ-MS/MS detection system, respectively.

The accuracy of detection method was assessed based on the recovery of these selected oxygenate compounds in two kinds of real water samples without any fuel oxygenates. These two water samples were spiked with the organics to two individual concentrations $(0.5$ and $5 \mu \mathrm{g} / \mathrm{L})$ [36]. The accuracy 
of P\&T-GC-QqQ-MS/MS detection method and HS-SPME-GC-QqQ-MS/MS detection method exhibited excellent recoveries. The accuracy of P\&T-GC-QqQ-MS/MS was ranging from 80.2 114.2\% for surface water and 80.5 120.1\% for groundwater. The accuracy of HS-SPME-GC-QqQ-MS/MS was ranging from $73.9 \sim 123.1 \%$ for surface water and $73.7 \sim 117.4 \%$ for groundwater as shown in Tables S2 and S3.

Chromatograms of the extracted quantitative identification ions obtained in P\&T-GC-QqQ-MS/MS system and HS-SPME-GC-QqQ-MS/MS system are shown in Figure S2.

\section{Conclusions}

In this study, two typical and reliable preparation technologies (P\&T and HS-SPME) were optimized for simultaneous detection of fuel oxygenates. Both of the two preparation methods provided excellent chromatographic resolution in subsequently GC-QqQ-MS/MS detection system. The precursor ions and product ions of these detected fuel oxygenates in this study were selected and identified with the optimized GC-QqQ-MS/MS operation parameters. Optimizations of P\&T and HS-SPME process were conducted comprehensively. The LODs and LOQs of these selected oxygenate compounds were discovered to be $0.52 \sim 32 \mathrm{ng} / \mathrm{L}$ in P\&T-GC-QqQ-MS/MS detection system method and 0.11 151 ng/L in HS-SPME-GC-QqQ-MS/MS detection system. Meanwhile, the intra-day and inter-day precision in this study for these selected oxygenate compounds were found in the range of $1.99 \sim 8.87 \%$ and $1.18 \sim 12.7 \%$ with the P\&T-GC-QqQ-MS/MS detection system, 1.19 9.65\% and 1.09 9.78\% with the HS-SPME-GC-QqQ-MS/MS detection system, respectively. For BTEX, the HS-SPME-GC-QqQ-MS/MS system provided outstanding detection performance because of the lower LODs obtained. However, for other selected compounds, the P\&T-GC-QqQ-MS/MS system offered lower LODs. Detection results indicated that both P\&T and HS-SPME pretreatment methods can be used to conduct simple and rapid preparation of water samples for fuel oxygenates detection, with good linearity, repeatability, precision, low LODs in the GC-QqQ-MS/MS detection system.

Supplementary Materials: The following are available online at http://www.mdpi.com/2073-4441/12/8/2266/s1, Figure S1: the mass spectra of the twelve analytes. (A) Full scan spectra in EI mode; (B) daughter scan spectra of quantitative ions; (C) daughter scan spectra of qualitative ions, Figure S2: chromatogram of quantitative identification ions of the twelve analytes $(5 \mu \mathrm{g} / \mathrm{L})$ in MRM: (A) PT-GC-MS/MS chromatogram; (B) HS-SPME-GC-MS/MS chromatogram, Table S1: name, segments, retention time, dwell time, precursors and product ions of quantitative transition and confirmation transition, and collision energy for the twelve analytes, Table S2: linearity of standard calibration curves, LODs, LOQs, method precision and validity for the twelve analytes using the P\&T-GC-QqQ-MS/MS methodology, Table S3: linearity of standard calibration curves, LODs, LOQs, method precision and validity for the twelve analytes using the HS-SPME-GC-MS/MS methodology.

Author Contributions: Methodology, K.Z.; software, Y.L.; formal analysis Q.S. and L.H.; data curation, M.Z.; writing —original draft preparation, K.Z.; writing—review and editing, Y.L. and K.Z.; supervision, K.Z.; project administration, Y.L. and K.Z.; funding acquisition, K.Z. and Y.L. All authors have read and agreed to the published version of the manuscript.

Funding: This work was financially supported by the Project of Introducing and Cultivating Young Talent in the Universities of Shandong Province and the Natural Science Foundation of Shandong Province (No. ZR2017BEE016).

Acknowledgments: We are grateful for assistance with Shandong Provincial Key Laboratory of Water and Soil Conservation and Environmental Protection, College of Resources and Environment, Linyi University, Linyi, 276000, China.

Conflicts of Interest: The authors declare no competing financial interests.

\section{References}

1. De Castro Sena, S.R.; de Barros Neto, E.L.; Pereira, C.G. Effect of ethyl octanoate and ethyl oleate on the properties of gasoline fuel mixture. Energy Fuels 2019, 33, 9429-9436. [CrossRef]

2. Hoekman, S.K.; Leland, A. Literature review on the effects of organometallic fuel additives in gasoline and diesel fuels. SAE Int. J. Fuels Lubr. 2018, 11, 105-124. [CrossRef]

3. Nadim, F.; Zack, P.; Hoag, G.E. United States experience with gasoline additives. Energy Policy 2001, $29,1-5$. [CrossRef] 
4. Lindsey, B.D.; Ayotte, J.D.; Jurgens, B.C.; Desimone, L.A. Using groundwater age distributions to understand changes in methyl tert-butyl ether (MtBE) concentrations in ambient groundwater, northeastern United States. Sci. Total Environ. 2017, 579, 579-587. [CrossRef] [PubMed]

5. Flanagan, S.M.; Levitt, J.P.; Ayotte, J.D. Trends in methyl tert-butyl ether concentrations in private wells in Southeast New Hampshire: 2005 to 2015. Environ. Sci. Technol. 2017, 51, 1168-1175. [CrossRef]

6. Ma, J.; Xiong, D.; Li, H.; Ding, Y.; Xia, X.; Yang, Y. Vapor intrusion risk of fuel ether oxygenates methyl tert-butyl ether (MTBE), tert-amyl methyl ether (TAME) and ethyl tert-butyl ether (ETBE): A modeling study. J. Hazard. Mater. 2017, 332, 10-18. [CrossRef]

7. Tang, Y.; Ren, Q.; Wen, Q.; Yu, C.; Xie, X.; Hu, Q.; Du, Y. Effect of methyl tert-butyl ether on adipogenesis and glucose metabolism in vitro and in vivo. J. Environ. Sci. 2019, 85, 208-219. [CrossRef]

8. Advisory Drinking Water. Consumer Acceptability Advice and Health Effects Analysis on Methyl Tertiary-Butyl Ether (MTBE); Office of Water, US EPA: Washington, DC, USA, 1997.

9. Rosell, M.; Lacorte, S.; Ginebreda, A.; Barceló, D. Simultaneous determination of methyl tert.-butyl ether and its degradation products, other gasoline oxygenates and benzene, toluene, ethylbenzene and xylenes in Catalonian groundwater by purge-and-trap-gas chromatography-mass spectrometry. J. Chromatogr. A 2003, 995, 171-184. [CrossRef]

10. McGregor, D. Tertiary-Butanol: A toxicological review. Crit. Rev. Toxicol. 2010, 40, 697-727. [CrossRef]

11. Vakili, M.; Rafatullah, M.; Salamatinia, B.; Ibrahim, M.H.; Ismail, N.; Abdullah, A.Z. Adsorption studies of methyl tert-butyl ether from environment. Sep. Purif. Rev. 2017, 46, 273-290. [CrossRef]

12. Pavón, J.L.P.; del Nogal Sánchez, M.; Laespada, M.E.F.; Cordero, B.M. Simultaneous determination of gasoline oxygenates and benzene, toluene, ethylbenzene and xylene in water samples using headspace-programmed temperature vaporization-fast gas chromatography-mass spectrometry. J. Chromatogr. A 2007, 1175, 106-111. [CrossRef] [PubMed]

13. US Environmental Protection Agency. National Primary Drinking Water Regulations; EPA 816-F-03-016; US EPA: Washington, DC, USA, 2003. Available online: http://www.epa.gov/safewater/contaminants (accessed on 5 August 2020).

14. Cassada, D.A.; Zhang, Y.; Snow, D.D.; Spalding, R.F. Trace analysis of ethanol, MTBE, and related oxygenate compounds in water using solid-phase microextraction and gas chromatography/mass spectrometry. Anal. Chem. 2000, 72, 4654-4658. [CrossRef]

15. Lee, M.R.; Chang, C.M.; Dou, J. Determination of benzene, toluene, ethylbenzene, xylenes in water at sub-ng $\mathrm{L}^{-1}$ levels by solid-phase microextraction coupled to cryo-trap gas chromatography-mass spectrometry. Chemosphere 2007, 69, 1381-1387. [CrossRef] [PubMed]

16. Dewsbury, P.; Thornton, S.F.; Lerner, D.N. Improved analysis of MTBE, TAME, and TBA in petroleum fuel-contaminated groundwater by SPME using deuterated internal standards with GC-MS. Environ. Sci. Technol. 2003, 37, 1392-1397. [CrossRef]

17. Tanabe, A.; Tsuchida, Y.; Ibaraki, T.; Kawata, K.; Yasuhara, A.; Shibamoto, T. Investigation of methyl tert-butyl ether levels in river-, ground-, and sewage-waters analyzed using a purge-and-trap interfaced to a gas chromatograph-mass spectrometer. J. Chromatogr. A 2005, 1066, 159-164. [CrossRef] [PubMed]

18. Bianchi, F.; Careri, M.; Marengo, E.; Musci, M. Use of experimental design for the purge-and-trap-gas chromatography-mass spectrometry determination of methyl tert.-butyl ether, tert.-butyl alcohol and BTEX in groundwater at trace level. J. Chromatogr. A 2002, 975, 113-121. [CrossRef]

19. Mezcua, M.; Agüera, A.; Hernando, M.D.; Piedra, L.; Fernández-Alba, A.R. Determination of methyl tert.-butyl ether and tert.-butyl alcohol in seawater samples using purge-and-trap enrichment coupled to gas chromatography with atomic emission and mass spectrometric detection. J. Chromatogr. A 2003, 999, 81-90. [CrossRef]

20. Zang, X.; Liang, W.; Chang, Q.; Wu, T.; Wang, C.; Wang, Z. Determination of volatile organic compounds in pen inks by a dynamic headspace needle trap device combined with gas chromatography-mass spectrometry. J. Chromatogr. A 2017, 1513, 27-34. [CrossRef]

21. Zwank, L.; Schmidt, T.C.; Haderlein, S.B.; Berg, M. Simultaneous determination of fuel oxygenates and BTEX using direct aqueous injection gas chromatography mass spectrometry (DAI-GC/MS). Environ. Sci. Technol. 2002, 36, 2054-2059. [CrossRef]

22. Kaykhaii, M.; Linford, M.R. Application of microextraction techniques including SPME and MESI to the thermal degradation of polymers: A review. Crit. Rev. Anal. Chem. 2017, 47, 172-186. [CrossRef] 
23. Kędziora-Koch, K.; Wasiak, W. Needle-based extraction techniques with protected sorbent as powerful sample preparation tools to gas chromatographic analysis: Trends in application. J. Chromatogr. A 2018, 1565, 1-18. [CrossRef] [PubMed]

24. Lorenzo-Parodi, N.; Kaziur, W.; Stojanović, N.; Jochmann, M.A.; Schmidt, T.C. Solventless microextraction techniques for water analysis. TrAC-Trend Anal. Chem. 2019, 113, 321-331. [CrossRef]

25. Avino, P.; Russo, M.V. A comprehensive review of analytical methods for determining persistent organic pollutants in air, soil, water and waste. Curr. Org. Chem. 2018, 22, 939-953. [CrossRef]

26. Hübschmann, H.J. Handbook of GC-MS: Fundamentals and Applications; John Wiley \& Sons: Hoboken, NJ, USA, 2015.

27. Liu, Y.; Su, M.; Zhang, Y.D.; Li, W. Influence rule of organic solvents methanol from sample preparation on degradation rate and mechanism of atrazine in UV-based oxidation processes. Acta Chim. Sin. 2019, 77, 72-83. [CrossRef]

28. European Commission. Commission Decision 2002/657/EC of 12 August 2002 Implementing Council Directive 96/23/EC Concerning the Performance of Analytical Methods and the Interpretation of Result. Off. J. Eur. Commun. 2002, 221, 8-36.

29. Sánchez-Avila, J.; Fernandez-Sanjuan, M.; Vicente, J.; Lacorte, S. Development of a multi-residue method for the determination of organic micropollutants in water, sediment and mussels using gas chromatography-tandem mass spectrometry. J. Chromatogr. A 2011, 1218, 6799-6811. [CrossRef]

30. Liu, Y.; Zhu, K.; Su, M.; Zhu, H.; Lu, J.; Wang, Y.; Dong, J.; Qin, H.; Wang, Y.; Zhang, Y. Influence of solution $\mathrm{pH}$ on degradation of atrazine during $\mathrm{UV}$ and $\mathrm{UV} / \mathrm{H}_{2} \mathrm{O}_{2}$ oxidation: Kinetics, mechanism, and degradation pathways. RSC Adv. 2019, 9, 35847-35861. [CrossRef]

31. Deng, X.; Liang, G.; Chen, J.; Qi, M.; Xie, P. Simultaneous determination of eight common odors in natural water body using automatic purge and trap coupled to gas chromatography with mass spectrometry. J. Chromatogr. A 2011, 1218, 3791-3798. [CrossRef]

32. Yuan, B.; Li, F.; Xu, D.; Fu, M.L. Comparison of two methods for the determination of geosmin and 2-methylisoborneol in algae samples by stable isotope dilution assay through purge-and-trap or headspace solid-phase microextraction combined with GC/MS. Anal. Methods 2013, 5, 1739-1746. [CrossRef]

33. Penalver, A.; Pocurull, E.; Borrull, F.; Marce, R.M. Trends in solid-phase microextraction for determining organic pollutants in environmental samples. TrAC-Trend Anal. Chem. 1999, 18, 557-568. [CrossRef]

34. Liu, Y.; Duan, J.; Li, W.; Lai, Q.; Saint, C.P.; Mulcahy, D. Determination of volatile disinfection byproducts in water by gas chromatography-triple quadrupole mass spectrometry. Anal. Lett. 2015, 48, 188-203. [CrossRef]

35. Office of Pesticide Programs, US Environmental Protection Agency. Assigning Values to Non-Detected/ Non-Quantified Pesticide Residues in Human Health Food Exposure Assessments; Office of Pesticide Programs, US Environmental Protection Agency: Washington, DC, USA, 2000.

36. Liu, Y.; Duan, J.; Li, W. Determination of Ten Kinds of Haloacetic Acids in Water by GC-EI-MS /MS. Chin. J. Anal. Chem. 2014, 42, 77-82.

(C) 2020 by the authors. Licensee MDPI, Basel, Switzerland. This article is an open access article distributed under the terms and conditions of the Creative Commons Attribution (CC BY) license (http://creativecommons.org/licenses/by/4.0/). 